\title{
Structure and Functional Characteristics of Rat's Left Ventricle Cardiomyocytes under Antiorthostatic Suspension of Various Duration and Subsequent Reloading
}

\author{
I. V. Ogneva, T. M. Mirzoev, N. S. Biryukov, O. M. Veselova, and I. M. Larina \\ State Scientific Center of Russian Federation, Institute of Biomedical Problems of Russian Academy of Sciences, 76-a, \\ Khoroshevskoyoe Shosse, Moscow 123007, Russia \\ Correspondence should be addressed to I. V. Ogneva, iogneva@yandex.ru
}

Received 5 March 2012; Revised 17 May 2012; Accepted 1 June 2012

Academic Editor: Michael Kalafatis

Copyright ( $) 2012$ I. V. Ogneva et al. This is an open access article distributed under the Creative Commons Attribution License, which permits unrestricted use, distribution, and reproduction in any medium, provided the original work is properly cited.

\begin{abstract}
The goal of the research was to identify the structural and functional characteristics of the rat's left ventricle under antiorthostatic suspension within 1, 3, 7 and 14 days, and subsequent 3 and 7-day reloading after a 14-day suspension. The transversal stiffness of the cardiomyocyte has been determined by the atomic force microscopy, cell respiration-by polarography and proteins contentby Western blotting. Stiffness of the cortical cytoskeleton increases as soon as one day after the suspension and increases up to the 14th day, and starts decreasing during reloading, reaching the control level after 7 days. The stiffness of the contractile apparatus and the intensity of cell respiration also increases. The content of non-muscle isoforms of actin in the cytoplasmic fraction of proteins does not change during the whole experiment, as does not the beta-actin content in the membrane fraction. The content of gamma-actin in the membrane fraction correlates with the change in the transversal stiffness of the cortical cytoskeleton. Increased content of alpha-actinin-1 and alpha-actinin-4 in the membrane fraction of proteins during the suspension is consistent with increased gamma-actin content there. The opposite direction of change of alpha-actinin-1 and alpha-actinin- 4 content suggests their involvement into the signal pathways.
\end{abstract}

\section{Introduction}

Exposure to microgravity causes various changes in the human cardiovascular system, particularly a cephalic fluid shift in the cranial direction $[1,2]$ and a change in the heart's systolic volume [3-5].

In order to simulate most of the effects in the human body under weightlessness, the model of antiorthostatic suspension by the tail is used with rodents, such as rats. It has been demonstrated that the effects typical of the muscle and bone tissue in microgravity can be satisfactorily reproduced in ground experiments using antiorthostatic suspension [6, 7].

However, the existing data about changes in the cardiovascular system are quite contradicting. Most researchers observe fluid shift and presence of hypovolemia in rats during the antiorthostatic suspension [8-10]. Shellock et al. [11] demonstrated that the intensity of change depends on the suspension angle. For instance, central venous pressure increased in rats suspended at $45^{\circ}$ and $20^{\circ}$ and did so reliably more in the first case than in the second case as soon as after 8 hours of suspension. After 24 hours of suspension, this value in rats suspended at $20^{\circ} \mathrm{C}$ did not differ from that of the control group, while the group of rats suspended at $45^{\circ}$ demonstrated a reliably higher value than the control group [11].

The effects of the early period cause increased volumetric load on the heart by activating cardiopulmonary receptors [12]. At the same time, Yin et al. [13] and Cui et al. [14] demonstrated that, after 4 weeks of suspension, the heart weight and arterial pressure of rats do not change, while the pressure in the left ventricle decreases. The sensitivity of the baroreceptor reflex after 14 days of suspension also remains unchanged [15]. This data demonstrates that the effects of the acute period are already compensated by that time.

At the same time, there is data demonstrating a decreased contractility of the rat's heart as a result of long-term 
suspension [16-19]. At the cell level, Dunlap et al. [20] demonstrated that the maximum contraction force of singleskinned cardiomyocytes of rat decreased by $15 \%$ after 7 days of suspension, as did calcium sensitivity, which the authors believe may be related to a change in the level of expression of contractile proteins as a result of a the increased volumetric load on the heart.

A number of authors observed decreased contractility of the myocard and decreased oxygen consumption during long-term suspension [21, 22]. However, Bigard et al. [23] did not observe any changes in the intensity of cell respiration of rat's cardiomyocytes after 3 weeks of antiorthostatic suspension. At the same time, increased activity of oxidative ferments and mitochondrial creatin kinase was observed in the right ventricle of rats after a 2-week experiment [24].

Thus, to sum up the existing literature, we can state that, at early stages of antiorthostatic suspension, the volumetric load on the heart is increased, and increased activity of mitochondrial ferments is observed. Later, during long-term antiorthostatic suspension, no changes in the heart weight and arterial pressure were observed in rats, even though the central venous pressure decreased. The contractile ability of the myocard decreased, including on the level of single cardiomyocytes. At the same time, no changes were identified in the intensity of cell respiration during long-term suspension, although oxygen consumption by the heart did decrease.

We suggested that at least the initial stages of suspension increase the mechanical load on the cardiomyocytes, unlike the cells of skeletal muscles, which have a lesser load under these conditions. Then, at early stages of reloading, the fluid shift is reversed and the mechanical tension of the cardiomyocytes should decrease. Meanwhile, changes in mechanical tension of the skeletal muscles are in the opposite direction. Our earlier data confirm that the stiffness of the cortical cytoskeleton of the skeletal muscle fibres is decreased, possibly due to the destruction of submembrane F-actin and dissociation of actin-binding proteins due to a change in the mechanical tension of the skeletal muscle cell [25]. This is why this study examines the transversal stiffness and the content of a number of cytoskeletal proteins in the cardiomyocytes, and to determine the intensity of cell respiration at the early stage of antiorthostatic suspension and during the subsequent reloading.

\section{Materials and Methods}

The experiments have been performed with the tissue of the left ventricle of a Wistar rat ( $n=49$ animals) weighing from 225 to $255 \mathrm{~g}$. To simulate the microgravity conditions in rodents, antiorthostatic suspension was used according to the Ilyin-Novikov method modified by Morey-Holton et al. [7]. Control animals were housed at the vivarium conditions and received standard food and water ad libitum. The duration of suspension was $1,3,7$, and 14 days. Reloading within 3 and 7 days was performed in the same conditions as vivarium control. Short period of reloading (3 and 7 days) after long-term gravity disuse (14 days) is of fundamental importance for understanding the cellular mechanisms of the acute period of readaptation. The following groups were created: "Control”, “1-HS”, “3-HS”, "7-HS”, "14-HS”, “14HS + 3-R", and "14-HS + 7-R", with 7 animals in each group. All procedures with animals were approved by the biomedical ethics committee of the State Research Center of Russia at the Institute of Biomedical Problems of the Russian Academy of Sciences.

2.1. Atomic Force Microscopy. Cardiomyocytes were obtained from a part of the tissue of the rat's left ventricle using the standard method $[26,27]$, but without using Triton X100. Before the experiments, samples were stored at $-20^{\circ} \mathrm{C}$ in a buffer containing equal parts of relaxation solution $\mathrm{R}$ (20 mM MOPS, $170 \mathrm{mM}$ of potassium propionate, $2.5 \mathrm{mM}$ of magnesium acetate, $5 \mathrm{mM}$ of $\mathrm{K}_{2} \mathrm{EGTA}$, and $2.5 \mathrm{mM}$ of ATP) and glycerol.

On the day of the experiment, the samples were transferred to solution $\mathrm{R}$ where single glycerynized cardiomyocytes were singled out.

In order to obtain demembranized cardiomyocytes, single glycerynized cardiomyocytes in the R solution were incubated for 12 hours at $+4^{\circ} \mathrm{C}$ with the Triton X-100 detergent with the final concentration of $2 \% \mathrm{v} / \mathrm{v}$. Such concentration of the detergent used and the long incubation time enable completely removing the membranes of cardiomyocyte to analyze only the myofibrillar apparatus. After treatment with the detergent, the obtained demembranized cardiomyocytes were cleaned in the R solution.

In order to measure the transversal stiffness, the obtained cardiomyocytes were fixed on the bottom of the liquid cell of the atomic force microscope, attaching their tips with special Fluka shellac wax-free glue (Sigma). Depending on the series of experiments, the cell was filled either wih the relaxation solution R, or activation solution A (20 mM MOPS, $172 \mathrm{mM}$ of potassium propionate, $2,38 \mathrm{mM}$ of magnesium acetate, $5 \mathrm{mM}$ CaEGTA, $2.5 \mathrm{mM}$ of ATP), or rigor solution $\mathrm{Rg}$ (20 mM MOPS, $170 \mathrm{mM}$ of potassium propionate, $2,5 \mathrm{mM}$ of magnesium acetate, $5 \mathrm{mM}$ of $\mathrm{K}_{2}$ EGTA). All contractions of the cardiomyocyte were isometric since the tips of the cardiomyocytes were fixed.

All experiments were conducted at $+16^{\circ} \mathrm{C}$.

Atomic force microscopy was used in order to determine the transversal stiffness of various compartments of the cardiomyocyte. The method of obtaining images of the cardiomyocyte surfaces to perform local measurements of transversal stiffness has been described in detail earlier [25, $28,29]$.

Measurements of transversal stiffness of both glycerynized and Triton X-100-treated cardiomyocytes were conducted using the Solver-P47-Pro platform (NT-MDT, Russia). The indentation depth was $150 \mathrm{~nm}$. We tested at least 21 cardiomyocytes from each sample $(n=147$ at least, from each group).

The results were processed in a special program in MatLab 6.5.

2.2. Cell Respiration by Polarography. A part of the tissue of the left ventricle was immediately placed into cold solution A $\left(2.77 \mathrm{mM}\right.$ of $\mathrm{CaK}_{2}$ EGTA, $7.23 \mathrm{mM}$ of $\mathrm{K}_{2}$ EGTA, $6.56 \mathrm{mM}$ of $\mathrm{MgCl}_{2} \cdot 6 \mathrm{H}_{2} \mathrm{O}, 0.5 \mathrm{mM}$ of DTT, $50 \mathrm{mM}$ of KMes, $20 \mathrm{mM}$ 
of imidazole, $20 \mathrm{mM}$ of taurine, $5.3 \mathrm{mM}$ of ATP, $15 \mathrm{mM}$ of phosphocreatine, $\mathrm{pH}=7.1$ ), where it was split into bunches of cardiomyocytes 3-4 mm long and about $1 \mathrm{~mm}$ thick. Then, the fibres were incubated in solution A with saponin $(50 \mu \mathrm{g} / \mathrm{mL})$ for 30 minutes with slight stirring, at $+4^{\circ} \mathrm{C}$, to partially skin the membrane. After that, fibre bunches were cleared of saponin for 10 minutes in solution $\mathrm{B}(2.77 \mathrm{mM}$ of $\mathrm{CaK}_{2}$ EGTA, $7.23 \mathrm{mM}$ of $\mathrm{K}_{2}$ EGTA, $1.38 \mathrm{mM}$ of $\mathrm{MgCl}_{2}$, $0.5 \mathrm{mM}$ of DTT, $100 \mathrm{mM}$ of KMes, $20 \mathrm{mM}$ of imidazole, $20 \mathrm{mM}$ of taurine, $3 \mathrm{mM}$ of $\mathrm{K}_{2} \mathrm{HPO}_{4}, \mathrm{pH}=7.1$ ).

Oxygen adsorption rate was evaluated using the Saks polarography method [30]. Bunches of skinned cardiomyocytes were incubated in solution B with $2 \mathrm{mg} / \mathrm{mL}$ of bovine serum albumin (BSA) free of fatty acids. For exogenous substrates of the respiratory chain, we used a mix of $5 \mathrm{mM}$ of glutamate and $2 \mathrm{mM}$ of malate, and added $1 \mathrm{mM}$ of ADP to determine the maximum respiration rate. Changes of oxygen concentration were measured using the Clark's electrode and YSI Model 53 Oxygen Monitor (Yellow Spring Instrument Co., USA) at $+22^{\circ} \mathrm{C}$. The solubility of oxygen in $1 \mathrm{~mL}$ of the incubation environment at this temperature was assumed at 460 ng-at [31].

The following parameters of respiration were measured: $V_{0}$-basal oxygen consumption rate, $V_{\mathrm{Glu}+\mathrm{Mal}}$-respiration rate on substrates ( $5 \mathrm{mM}$ of glutamate $+2 \mathrm{mM}$ of malate), $V_{\max }$-maximum respiration rate (in the presence of $1 \mathrm{mM}$ of ADP). After the measurements, the cardiomyocytes were extracted from the polarographic cell, dried at $+95^{\circ} \mathrm{C}$ and weighed to calculate the rates per mg of dry weight. Respiratory control $(\mathrm{RC})$ was calculated as the respiration rate in the presence of ADP to the respiration rate on exogenic substrates. We tested $n=7$ samples from each group.

2.3. Western Blotting. In order to determine the protein content, a part of the rat's left ventricle was frozen at the temperature of liquid nitrogen. The method described in Vitorino et al. [32] was used to prepare tissue extracts and obtain the membrane and cytoplasmic fraction of proteins. Denaturating polyacrylamide gel electrophoresis was performed using the Laemmly method at the Bio-Rad system (USA), as described earlier [25]. Basing on the measured concentration of total fraction protein content, equal amounts of protein were added to each hole. The transfer to the nitrocellulose membrane was performed using the method of Towbin et al. [33].

In order to determine each protein, specific monoclonal primary antibodies based on mice immunoglobulines were used (Santa Cruz Biotechnology, Inc.) in the manufacturerrecommended dilutions: $1: 200$ for desmin, $1: 300$ for betaactin, $1: 100$ for gamma-actin, $1: 100$ for alpha-actinin-1, $1: 100$ for alpha-actinin-4-1:100. For secondary antibodies, we used biotinylated goat antibodies against mice IgG (Santa Cruz Biotechnology, Inc.) diluted 1:5000.

In order to determine alpha-actinin-2 content, specific monoclonal primary antibodies based on rabbit immunoglobulines were used (Santa Cruz Biotechnology, Inc.) diluted $1: 200$ as recommended by the manufacturer. For secondary antibodies, we used biotinylated goat antibodies against rabbit IgG (Sigma, Germany) diluted 1:5000.
Afterwards, all membranes were treated with streptavidin conjugated with horseradish peroxidase (Sigma, Germany) diluted 1:5000. Protein lines were identified using 3,3'diaminobenzidine (Merck, USA).

We tested $n=7$ samples from each group.

2.4. Statistical Analysis. The results obtained during the experiments were statistically processed with ANOVA, using a post hoc $t$-test with the confidence level $P<0.05$ to evaluate the certainty of difference between the groups. The data was represented as $\mathrm{M} \pm \mathrm{SE}$, where $\mathrm{M}$ is the average arithmetic value and $\mathrm{SE}$ is the average value error.

\section{Results}

3.1. Transversal Stiffness of Various Parts of the Sarcolemma and Contractile Apparatus of Fibres of Rat's Left Ventricle during Antiorthostatic Suspension and Subsequent Reloading. In the control group (Table 1), the transversal stiffness of the contractile apparatus of fibers of the left ventriculum of rat near the semisarcomere, that is, between the Z-disk and the M-band increased in the sequence relaxation-activation rigor. This value increased significantly from relaxation to activation. This situation did not change after 24 hours of antiorthostatic suspension.

However, in three days, the stiffness of the contractile apparatus significantly increased near the semisarcomere both in the relaxed and in the activated/rigor states compared to similar states in the control group. This increase was even more prominent seven days after antiorthostatic suspension. 3 -day reloading after 14-day suspension caused significant reduction in the transversal stiffness in all states relative to both the 14-HS group and the control group. However, after seven days of reloading, the transversal stiffness returned to the level of the control group.

Nevertheless, during the antiorthostatic suspension and subsequent reloading, when contraction was activated, the stiffness of the semisarcomere reliably decreased compared to the relaxed state.

At the M-line, the stiffness of the contractile apparatus of fibers of the left ventricular of rat was higher than the stiffness of the semisarcomere. During antiorthostatic suspension, the transversal stiffness of the $\mathrm{M}$ line remained unchanged, but it significantly decreased after three days of reloading that followed a 14-day suspension. After 7 days of reloading, the transversal stiffness of the M-line did not differ from the control group values.

The transversal stiffness of the Z-disk is significantly higher than in the semisarcomere and the $M$ band. As described above, it also increased during activation and rigor. The changes in transversal stiffness of the Z-disk over time were similar to those of the M-line, except that it decreased more after 3 days of reloading.

The transversal stiffness of various segments of glycerynized fibers of the left ventricular of rat (Table 2) in the control group increased during the activation of contraction and in rigor compared to the relaxed state. 
TABle 1: Transversal stiffness ( $\mathrm{pN} / \mathrm{nm}$ ) of isolated rat's Triton-treated left ventricular myocytes in liquid in relaxed, calcium activated (pCa $=4.2$ ) and rigor states under gravitational unloading and subsequent reloading.

\begin{tabular}{|c|c|c|c|}
\hline \multirow[b]{2}{*}{ Group } & \multicolumn{3}{|c|}{ State } \\
\hline & Relaxed & Activated $(\mathrm{pCa}=4.2)$ & Rigor \\
\hline \multicolumn{4}{|c|}{ Transversal stiffness of the half-sarcomere area $k_{\perp \mathrm{ca}}$} \\
\hline Control $(n=165)$ & $7.1 \pm 0.4$ & $11.0 \pm 0.5^{@}$ & $13.2 \pm 0.5^{@}$ \\
\hline $1-\mathrm{HS}(n=153)$ & $6.8 \pm 0.3$ & $10.3 \pm 0.3^{@}$ & $12.9 \pm 0.3^{@}$ \\
\hline $3-\mathrm{HS}(n=149)$ & $8.2 \pm 0.3^{*}$ & $13.8 \pm 0.4^{*} / @$ & $14.7 \pm 0.3^{*} / @$ \\
\hline 7-HS $(n=148)$ & $8.9 \pm 0.3^{*}$ & $13.5 \pm 0.3 * / @$ & $15.3 \pm 0.3 * / @$ \\
\hline $14-\mathrm{HS}(n=157)$ & $8.7 \pm 0.4^{*}$ & $13.6 \pm 0.4^{*} /^{@}$ & $15.6 \pm 0.4^{*} /^{@}$ \\
\hline $14-\mathrm{HS}+3-\mathrm{R}(n=162)$ & $4.3 \pm 0.3^{*} / \$$ & $6.8 \pm 0.3^{*} / /^{@}$ & $8.2 \pm 0.5^{*} /{ }^{@} \$$ \\
\hline $14-\mathrm{HS}+7-\mathrm{R}(n=151)$ & $7.7 \pm 0.3$ & $11.0 \pm 0.9^{@}$ & $13.4 \pm 0.6^{@}$ \\
\hline \multicolumn{4}{|c|}{ Transversal stiffness of the M-band area $k_{\perp \mathrm{ml}}$} \\
\hline Control & $9.9 \pm 0.6$ & $15.0 \pm 0.6^{@}$ & $16.4 \pm 0.5^{@}$ \\
\hline 1-HS & $8.9 \pm 0.5$ & $14.1 \pm 0.4^{@}$ & $15.8 \pm 0.5^{@}$ \\
\hline 3-HS & $9.3 \pm 0.5$ & $14.8 \pm 0.6^{@}$ & $16.3 \pm 0.5^{@}$ \\
\hline 7-HS & $10.6 \pm 0.4$ & $14.9 \pm 0.5^{@}$ & $16.5 \pm 0.8^{@}$ \\
\hline 14-HS & $9.8 \pm 0.5$ & $14.2 \pm 0.6^{@}$ & $15.7 \pm 0.3^{@}$ \\
\hline $14-\mathrm{HS}+3-\mathrm{R}$ & $6.2 \pm 0.3^{*} / \$$ & $12.6 \pm 0.4^{*} /{ }^{@} \$$ & $13.1 \pm 0.4^{*} /{ }^{@} / \$$ \\
\hline $14-\mathrm{HS}+7-\mathrm{R}$ & $9.3 \pm 0.4$ & $14.3 \pm 0.8^{@}$ & $17.1 \pm 0.5^{@}$ \\
\hline \multicolumn{4}{|c|}{ Transversal stiffness of the Z-disk area $k_{\perp Z d}$} \\
\hline Control & $16.0 \pm 1.3$ & $22.5 \pm 1.5^{@}$ & $24.5 \pm 0.9^{@}$ \\
\hline $1-\mathrm{HS}$ & $15.4 \pm 0.6$ & $21.6 \pm 0.3^{@}$ & $24.8 \pm 0.6^{@}$ \\
\hline 3-HS & $15.9 \pm 0.6$ & $23.4 \pm 0.7^{@}$ & $26.1 \pm 1.3^{@}$ \\
\hline 7-HS & $15.9 \pm 0.5$ & $21.7 \pm 0.3^{@}$ & $25.9 \pm 0.6^{@}$ \\
\hline 14-HS & $15.8 \pm 0.8$ & $21.9 \pm 0.9^{@}$ & $22.9 \pm 0.7^{@}$ \\
\hline $14-\mathrm{HS}+3-\mathrm{R}$ & $7.5 \pm 0.4^{*} / \$$ & $13.4 \pm 0.5^{*} /{ }^{@} / \$$ & $16.0 \pm 0.4^{*} / @ / \$$ \\
\hline $14-\mathrm{HS}+7-\mathrm{R}$ & $15.4 \pm 0.6$ & $21.4 \pm 0.5^{@}$ & $23.4 \pm 1.4^{@}$ \\
\hline
\end{tabular}

After one day of antiorthostatic suspension, the transversal stiffness of the sarcolemma between the Z-disk and Mband projections in the relaxed state significantly increased relative to the control values, but did not differ from the control values in the activated and rigor states. After three days of suspension, the transversal stiffness of the sarcolemma increased even more and continued to increase up to the 14th day, and it significantly differed from the control value in the relaxed, activated, and rigor states. Moreover, after 14 days of suspension, the transversal stiffness values of this area during activation and in rigor did not significantly differ from the values in the relaxed state. After 3 days of reloading, the transversal stiffness of the sarcolemma decreased compared to values in the 14-HS group, but only reached the levels of the control group by the 7 th day of reloading.

The transversal stiffness of the sarcolemma in the Mband projection in the relaxed state significantly increased compared to the control levels by the 3rd day of suspension and subsequently increased up to the 14th day. The transversal stiffness values in this area in the activated and rigor states did not differ from the control level. After 3 days of reloading following a 14-day suspension, the transversal stiffness of the membrane in the M-line projection decreased, but reached the control group level only after 7 days of reloading.
The transversal stiffness of the sarcolemma in the Z-disk projection significantly increased only by the 14 th day of suspension, significantly decreased after 3 days of reloading, and did not differ from the control group levels after 7 days.

3.2. Cell Respiration of Fibres of the Rat's Left Ventricle under Antiorthostatic Suspension and Subsequent Reloading (Table 3$)$. The basal respiration rate $\left(V_{0}\right)$ of the rat's left ventricle fibre increased by $43 \%(P<0.05)$ after 24 hours of antiorthostatic suspension compared to the same value in the control group. However, after three days of suspension, $V_{0}$ decreased, reaching the control group level, and subsequently remained unchanged during the antiorthostatic suspension. After 3 days of reloading following a 14-day suspension, the respiration rate on endogenous substrates was below the control group's level by 33\% $(P<0.05)$, while after 7 days of reloading it did not differ from the control level.

The respiration rate on exogenous substrated $\left(V_{\mathrm{Glu}+\mathrm{Mal}}\right)$ after one day of suspension increased by $88 \%(P<0.05)$ compared to the control group and remained high up to the 14 th day of suspension. After 3 days of reloading, this value decreased by $14 \%(P<0.05)$ compared to the 14 -HS group and was significantly less than the control group's. After 
TABle 2: Transversal stiffness ( $\mathrm{pN} / \mathrm{nm}$ ) of isolated rat's permeabilized left ventricular myocytes in liquid in relaxed, calcium activated (pCa $=4.2$ ) and rigor states under gravitational unloading and subsequent reloading.

\begin{tabular}{|c|c|c|c|}
\hline \multirow[b]{2}{*}{ Group } & \multicolumn{3}{|c|}{ State } \\
\hline & Relaxed & Activation $(\mathrm{pCa}=4.2)$ & Rigor \\
\hline \multicolumn{4}{|c|}{ Transversal stiffness of sarcolemma between the M-band and Z-disk projections $k_{\perp s}$} \\
\hline Control $(n=165)$ & $4.03 \pm 0.11$ & $9.1 \pm 0.4^{@}$ & $9.67 \pm 0.24^{@}$ \\
\hline $1-\mathrm{HS}(n=153)$ & $4.80 \pm 0.22 *$ & $9.5 \pm 0.5^{@}$ & $10.1 \pm 0.3^{@}$ \\
\hline 3 -HS $(n=149)$ & $6.22 \pm 0.29^{*}$ & $10.2 \pm 0.3^{*} /^{@}$ & $10.8 \pm 0.4^{*} /^{@}$ \\
\hline 7-HS $(n=148)$ & $7.79 \pm 0.12^{*}$ & $10.5 \pm 0.3 * / @$ & $13.3 \pm 0.4^{*} / @$ \\
\hline 14 -HS $(n=157)$ & $12.3 \pm 0.4^{*}$ & $12.9 \pm 0.4^{*}$ & $13.3 \pm 0.3^{*} / @$ \\
\hline $14-\mathrm{HS}+3-\mathrm{R}(n=162)$ & $6.4 \pm 0.5^{*} / \$$ & $7.5 \pm 0.3^{*} / \$$ & $8.4 \pm 0.6^{*} / \$ / @$ \\
\hline $14-\mathrm{HS}+7-\mathrm{R}(n=151)$ & $4.3 \pm 0.4$ & $8.9 \pm 0.5^{@}$ & $9.2 \pm 0.3^{@}$ \\
\hline \multicolumn{4}{|c|}{ Transversal stiffness of sarcolemma at the M-band projection $k_{\perp \mathrm{Mls}}$} \\
\hline Control & $2.85 \pm 0.12$ & $6.8 \pm 0.5^{@}$ & $7.4 \pm 0.6^{@}$ \\
\hline $1-\mathrm{HS}$ & $2.68 \pm 0.17$ & $6.6 \pm 0.3^{@}$ & $7.0 \pm 0.3^{@}$ \\
\hline 3-HS & $3.77 \pm 0.25^{*}$ & $6.7 \pm 0.4^{@}$ & $7.7 \pm 0.5^{@}$ \\
\hline 7-HS & $5.79 \pm 0.19^{*}$ & $6.9 \pm 0.3^{@}$ & $7.9 \pm 0.3^{@}$ \\
\hline 14-HS & $7.55 \pm 0.13^{*}$ & $7.9 \pm 0.6^{*}$ & $9.4 \pm 0.3 * / @$ \\
\hline $14-\mathrm{HS}+3-\mathrm{R}$ & $3.57 \pm 0.20 * / \$$ & $5.9 \pm 0.4^{\$} /^{@}$ & $6.3 \pm 0.3^{\$} /^{@}$ \\
\hline $14-\mathrm{HS}+7-\mathrm{R}$ & $3.1 \pm 0.3$ & $6.2 \pm 0.4^{@}$ & $7.0 \pm 0.6^{@}$ \\
\hline \multicolumn{4}{|c|}{ Transversal stiffness of sarcolemma at the Z-disk projection $k_{\perp \mathrm{Zds}}$} \\
\hline Control & $10.0 \pm 0.3$ & $14.5 \pm 1.2^{@}$ & $15.3 \pm 0.5^{@}$ \\
\hline 1-HS & $10.7 \pm 0.8$ & $15.4 \pm 0.3^{@}$ & $16.3 \pm 0.5^{@}$ \\
\hline $3-\mathrm{HS}$ & $10.6 \pm 0.3$ & $14.8 \pm 0.3^{@}$ & $15.2 \pm 0.7^{@}$ \\
\hline 7-HS & $10.4 \pm 0.3$ & $11.9 \pm 0.3^{@}$ & $16.5 \pm 0.3^{@}$ \\
\hline 14-HS & $17.2 \pm 0.4^{*}$ & $17.9 \pm 0.4^{*}$ & $18.2 \pm 0.5^{*} /^{@}$ \\
\hline $14-\mathrm{HS}+3-\mathrm{R}$ & $9.2 \pm 0.3^{*} / \$$ & $10.3 \pm 0.6^{*} / \$$ & $11.9 \pm 0.5^{*} / \$ /^{@}$ \\
\hline $14-\mathrm{HS}+7-\mathrm{R}$ & $9.9 \pm 0.7$ & $15.1 \pm 0.8^{@}$ & $15.6 \pm 0.4^{@}$ \\
\hline
\end{tabular}

${ }^{*} P<0.05$ as compared to the analogous state of the group "Control", ${ }^{\circledR} P<0.05$ as compared to the relaxed state at the same group, ${ }^{\$} P<0.05$ as compared to the analogous state of the group "14-HS".

TABLE 3: Cell respiration of the rat's left ventricular myocytes under gravitational unloading and subsequent reloading.

\begin{tabular}{|c|c|c|c|c|}
\hline \multicolumn{5}{|c|}{ Parameter } \\
\hline Group & $\begin{array}{c}V_{0}, \text { ng-atom } \mathrm{O} \cdot \\
\cdot \mathrm{min}^{-1} \cdot \mathrm{mg}^{-1}\end{array}$ & $\begin{array}{c}V_{\mathrm{Glu}+\mathrm{Mal}}, \text { ng-atom } \mathrm{O} \cdot \\
\cdot \mathrm{min}^{-1} \cdot \mathrm{mg}^{-1}\end{array}$ & $\begin{array}{l}V_{\max }, \text { ng-atom } \mathrm{O} . \\
\cdot \min ^{-1} \cdot \mathrm{mg}^{-1}\end{array}$ & Respiration ratio \\
\hline Control $(n=7)$ & $14.8 \pm 1.4$ & $15.9 \pm 0.9$ & $22.7 \pm 1.6$ & $1.46 \pm 0.11$ \\
\hline $1-\mathrm{HS}(n=7)$ & $21.2 \pm 1.9^{*}$ & $29.7 \pm 2.8^{*}$ & $49.0 \pm 5.1^{*}$ & $1.64 \pm 0.07$ \\
\hline 3 -HS $(n=7)$ & $16.3 \pm 1.1^{\&}$ & $26.0 \pm 1.5^{*}$ & $47.5 \pm 2.3^{*}$ & $1.91 \pm 0.21^{*}$ \\
\hline 7 -HS $(n=7)$ & $16.9 \pm 0.8^{\&}$ & $28.3 \pm 1.9^{*}$ & $44.9 \pm 2.1^{*}$ & $1.59 \pm 0.13$ \\
\hline $14-\mathrm{HS}(n=7)$ & $16.4 \pm 1.2^{\&}$ & $27.6 \pm 1.5^{*}$ & $44.5 \pm 2.1^{*}$ & $1.64 \pm 0.14$ \\
\hline $14-\mathrm{HS}+3-\mathrm{R}(n=7)$ & $9.9 \pm 0.6^{*} / 8 / \$$ & $13.6 \pm 0.7^{*} / \& / \$$ & $18.5 \pm 1.9^{*} / \& / \$$ & $1.44 \pm 0.12$ \\
\hline $14-\mathrm{HS}+7-\mathrm{R}(n=7)$ & $15.7 \pm 1.7$ & $17.2 \pm 1.4$ & $25.1 \pm 1.6$ & $1.58 \pm 0.15$ \\
\hline
\end{tabular}

${ }^{*} P<0.05$ as compared to the group "Control", ${ }^{\&} P<0.05$ as compared to the group " 1 -HS", $\$ P<0.05$ as compared to the group "14-HS".

7 days of reloading, $V_{\mathrm{Glu}+\mathrm{Mal}}$ did not differ from the control group level.

Changes in the maximum respiration rate determined by adding ADP $\left(V_{\max }\right)$ of rat's left ventricle fibre changed after suspension and after recovery were consistent with changes in the respiration rate on exogenous substrates $V_{\mathrm{Glu}+\mathrm{Mal}}$.

The estimated value reflecting the efficiency of coupling of oxidation and phosphorylation, known as respiratory control, increased after three days of antiorthostatic suspension by $31 \%(P<0.05)$ relative to the control group and then decreased and did not differ from the control group's during further suspension and subsequent reloading.

3.3. Cytoskeletal Protein Content in Rat's Left Ventricle Fibres during Antiorthostatic Suspension and Subsequent Reloading. Relative alpfa-actinin-2 content in the total protein (Figure 1) remained unchanged during antiorthostatic suspension. However, during the early period of readaptation 


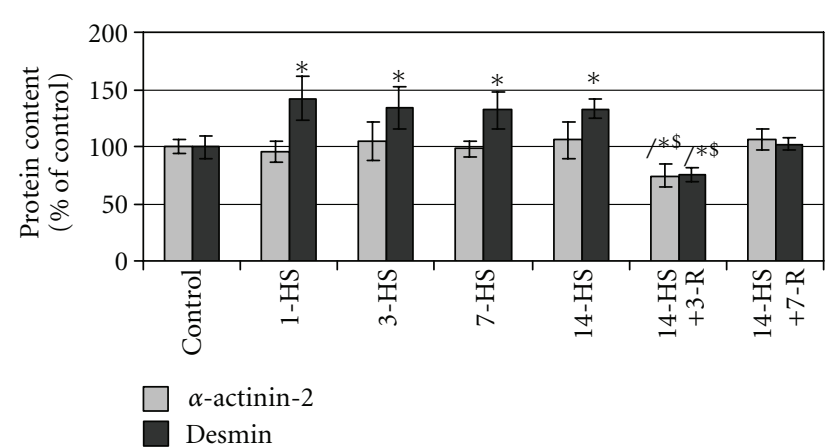

Figure 1: Protein content in the rat's left ventricular myocytes under gravitational unloading and subsequent reloading; $n=7$ samples for each group; ${ }^{*} P<0.05$ as compared to the group "Control", ${ }^{\$} P<0.05$ as compared to the group "14-HS".

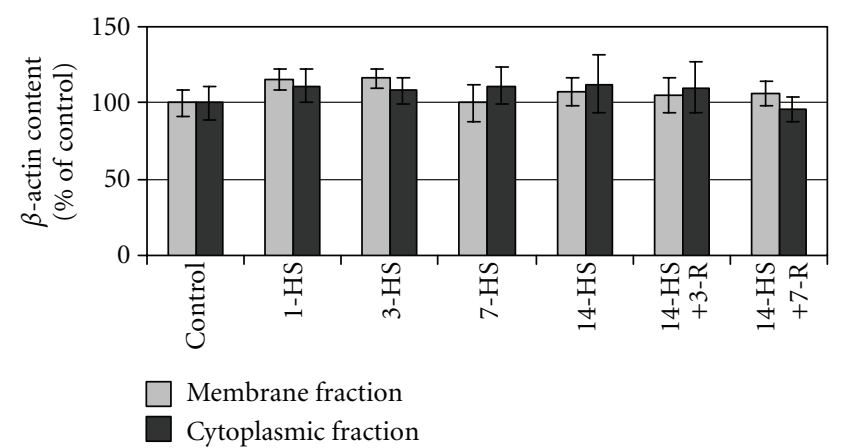

Figure 2: Beta-actin content in the rat's left ventricular myocytes under gravitational unloading and subsequent reloading; $n=7$ samples for each group; ${ }^{*} P<0.05$ as compared to the group "Control", ${ }^{\$} P<0.05$ as compared to the group "14-HS".

(after 3 days) following the 14-day suspension, its content reduced by $26 \%$ and returned to the control group level after 7 days of reloading.

Desmin content (Figure 1) during suspension increased by $42 \%$ after one day, and exceeded the control group's by $32-34 \%$ on the $3 \mathrm{rd}, 7 \mathrm{th}$, and 14 th day. During the reloading period following the 14-day suspension, desmin content, as well as alpha-actinin- 2 content, reduced by $24 \%$ after 3 days and did not differ from the control group's after 7 days of reloading.

Beta-actin content (Figure 2) in the cytoplasmic fraction and in the membrane fraction of proteins did not differ from the control group level under antiorthostatic suspension and subsequent reloading.

Gamma-actin content (Figure 3) in the cytoplasmic fraction of proteins, just like beta-actin content, did not change during the suspension and subsequent reloading. In the membrane fraction, gamma-actin content exceeded the control level by $44 \%$ after 1 day of suspension, by $80 \%$ after 3 days, by $130 \%$ after 7 days, and by $150 \%$ after 14 days. After 3 days of reloading following a 14-day suspension, gamma-actin content in the membrane fraction of proteins significantly decreased to the control group's level and remained the same after 7 days of reloading.

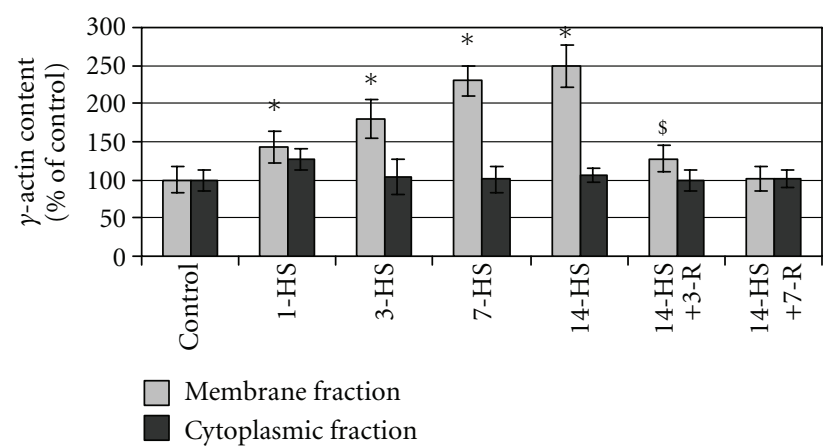

Figure 3: Gamma-actin content in the rat's left ventricular myocytes under gravitational unloading and subsequent reloading; $n=7$ samples for each group; ${ }^{*} P<0.05$ as compared to the group "Control", $\$ P<0.05$ as compared to the group "14-HS".

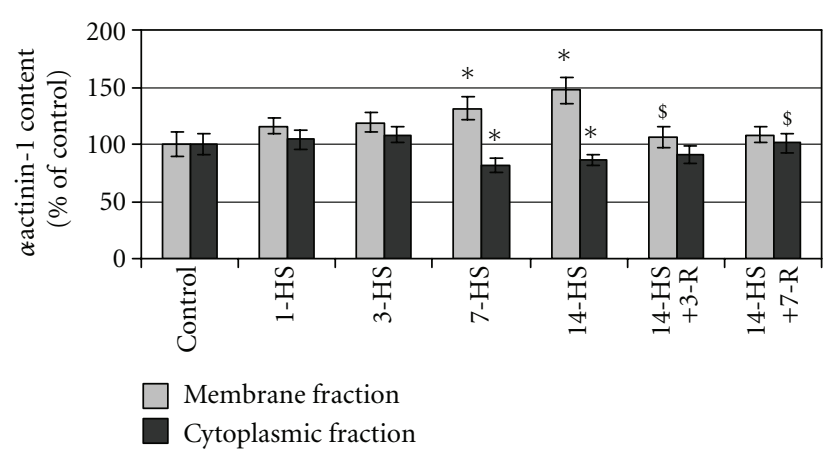

Figure 4: Alpha-actinin-1 content in the rat's left ventricular myocytes under gravitational unloading and subsequent reloading; $n=7$ samples for each group; ${ }^{*} P<0.05$ as compared to the group "Control", $\$ P<0.05$ as compared to the group "14-HS".

Alpha-actinin-1 content (Figure 4) in the cytoplasmic fraction of proteins significantly decreased by $19 \%$ after 7 days of antiorthostatic suspension and by $14 \%$ after 14 days. During the reloading, its content increased and did not differ from that of the control group. For alpha-actinin-1 content in the membrane fraction of proteins, the trends were different. After 7 days of suspension, its content increased by $31 \%$, and by $47 \%$ after 14 days. During the reloading, its content decreased and did not differ from that of the control group.

Alpha-actinin-4 content (Figure 5) in the cytoplasmic fraction of proteins, unlike alpha-actinin-1 level, increased and exceeded the control level by $35 \%$ after 3 days, by $82 \%$ after 7 days, and by $93 \%$ after 14 days. During the reloading following 14 days of suspension, its content started to significantly decrease after 7 days of readaptation, but still exceeded the control group level by 59\%. Alpha-actinin-4 content in the membrane fraction of proteins changed in a similar way to alpha-actinin- 1 content in the membrane fraction. It increased by $51 \%$ after 1 day of suspension, by $59 \%$ after 3 days of suspension, by $55 \%$ after 7 days of suspension, and by $75 \%$ after 14 days of suspension. During the reloading following 14 days of suspension, its content 


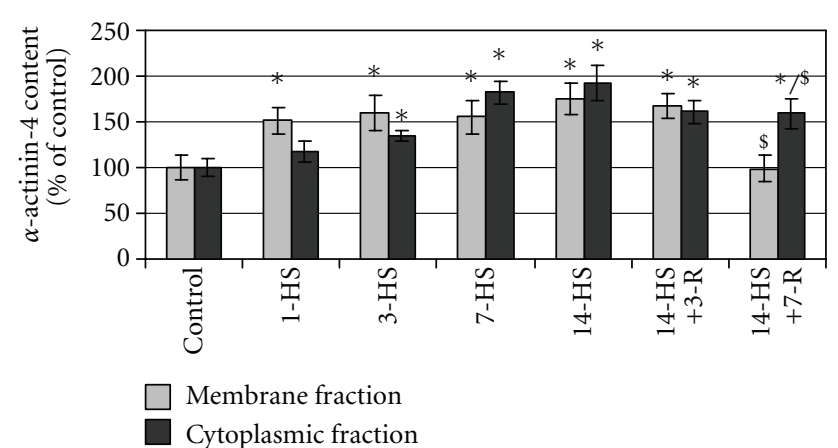

Figure 5: Alpha-actinin-4 content in the rat's left ventricular myocytes under gravitational unloading and subsequent reloading; $n=7$ samples for each group; ${ }^{*} P<0.05$ as compared to the group "Control", $\$ P<0.05$ as compared to the group "14-HS".

started decreasing and reached the control level by the 7th day of readaptation.

\section{Discussion}

The results of this research suggest that antiorthostatic suspension causes a number of changes in the cardiomyocytes of rats.

The results of AFM measurements of the stiffness of the myofibrillar apparatus of rat's left ventricle cardiomyocytes suggest that transversal stiffness of the Z-disk and M-line in the relaxed state was $16.0 \pm 1.3 \mathrm{pN} / \mathrm{nm}$ and $9.9 \pm 0.6 \mathrm{pN} / \mathrm{nm}$, respectively, which is close to the results described in Zhu et al. [27] that have been obtained by analyzing bunches of myofibrils from the left ventricle of adult cows, where the stiffness of the Z-disk was $18 \pm 2.5 \mathrm{pN} / \mathrm{nm}$, and that of the $\mathrm{M}$-line was $11 \pm 0.5 \mathrm{pN} / \mathrm{nm}$. In the rigor state, the transversal stiffness of the Z-disk and the M-line, according to our data, was $24.5 \pm 0.9 \mathrm{pN} / \mathrm{nm}$ and $16.4 \pm 0.5 \mathrm{pN} / \mathrm{nm}$, respectively, while in Zhu et al. [27] they were at $25 \pm 2 \mathrm{pN} / \mathrm{nm}$ and $17 \pm 0.5 \mathrm{pN} / \mathrm{nm}$, respectively.

In the course of antiorthostatic suspension, the transversal stiffness of the contractile apparatus of the rat's left ventricle cardiomyocytes near the Z-disk and the M-line remained unchanged. However, after 3 days of reloading following a 14-day suspension, these parameters significantly decreased. Akiyama et al. [34] demonstrated that calpain treatment during the first minutes caused significant decrease of transversal stiffness of the Z-disk in single myofibrils in rigor state of the cardiac muscle of newly born rats from $25.8 \mathrm{pN} / \mathrm{nm}$ before the treatment to $11 \mathrm{pN} / \mathrm{nm}$ after the treatment, which the authors explained by the destruction of alpha-actinin-2. This is why we have analyzed the relative content of this protein in the course of suspension and subsequent reloading relative to the control group. Alphaactinin-2 content did not change during the suspension, decreased by $26 \%$ after 3 days of reloading and returned to the control level after 7 days of readaptation following 14 days of suspension, which is consistent with our Zdisk transversal stiffness measurements and the results of Akiyama et al. [34].
The transversal stiffness of the contractile apparatus near the semisarcomere increased after 3 days and remained increased up to the 14th day of antiorthostatic suspension. The changes in the transversal stiffness as a mechanical parameter reflect the changes in the structure in question. Since the contractile apparatus is a significantly nonuniform structure, any changes in the transversal stiffness may be caused due to a number of physical and chemical factors (temperature, $\mathrm{pH}$, and others), and the phosphorylation level of the light chains of myosin or interfilament spacing. However, in all of the experiments, we have conducted the physical and chemical parameters that remained stable. Changes in the level of phosphorylation of light myosin chains may cause higher probability of closing crossbridges [35] and, consequently, lead to higher transversal stiffness. Thus, Persechini et al. [36] demonstrated that phosphorylation of light myosin chains causes increased strain in activated fibres. The number of closed crossbridges is evaluated by the maximum contractile force and calcium sensitivity. However, Dunlap et al. [20] in their experiments noted a reduction in the maximum contractile force and calcium sensitivity of the rat's cardiomyocytes after 7 days of antiorthostatic suspension. At the same time, an increase of the transversal stiffness of the contractile apparatus of cardiomyocytes in the absence of any increase of cell dimensions may cause a reduced maximum contractile force, which has been demonstrated by Lieber et al. [26], and may explain the reasons for reduced contractility of the myocard during antiorthostatic suspension. The effect of changes of the interfilament spacing on the transversal stiffness was shown by Matsubara et al. [37], Xu et al. [38], and Ranatunga et al. [39] in experiments with osmotic agents. Stretching of the cardiomyocyte as a result of increased volumetric load on the heart may theoretically cause the interfilament spacing to decrease and the transversal stiffness to subsequently increase, thus decreasing the maximum contractile force of a single cardiomyocyte and the contractility of the myocard in general. However, this assumption requires further experimental proof.

On the other hand, the observed decrease of the maximum contractile force and calcium sensitivity of single cardiomyocytes of the rat during antiorthostatic suspension [20] may be related not just to the possible change in the inter-filament spacing, but also due to changes in the muscle fibre structure. Synchronous contraction of single myofibrils is partially due to their structural link provided by desmin, the protein that forms intermediate filaments. At early stages of antiorthostatic suspension, we observe a decrease of desmin content $[29,40]$ in the soleus muscle, where a decrease of calcium sensitivity and the maximum contractile force of the fibre was also observed [41], which is apparently related to activation of calpain, the calciumdependent protease, under these conditions [40]. Our results in this research suggest that relative desmin content in the total protein increases, unlike in the soleus muscle, as soon as on the first day, and remains higher than the control group level within the whole period of antiorthostatic suspension, but decreases below the control group level after 3 days of reloading. This is why we can suggest that both factors 
(increase of desmin content and possible change of the interfilament spacing) may have affected the increase of transversal stiffness of the contractile apparatus in cardiomyocytes.

At the same time, desmin is one of the key proteins determining localization of mitochondria [42]. In the absence thereof, mitochondria sustain structural and functional damage [43]. Furthermore, the function of mitochondria may be affected by changes of their form due to stretching or compression of the membrane, which is mediated by the cytoskeleton [44]. Thus, Milner et al. [45] discovered abnormal agglomerations of subsarcolemmal mitochondria clusters and swelling of mitochondria with simultaneous degeneration of their matrix in the soleus muscle fibre of null-desmin mice. Moreover, the same authors measured the intensity of cell respiration and showed that both the oxygen consumption rate and ADP dissociation constant were reliably decreased compared to the same values of mice in the control group [45]. With regard to cardiomyocytes, Saks et al. [46] showed that oxygen consumption rate depends on the state of the cytoskeleton. However, Bigard et al. [23] did not observe any changes in the cell respiration rate of rat's cardiomyocytes after 3 weeks of antiorthostatic suspension. Our results suggest that basal cell respiration rate remained nearly unchanged during antiorthostatic suspension, and only slightly increased (although significantly) during the first day. The respiration rate after adding glutamate and malate to the environment, as well as the maximum respiration rate significantly increased as soon as after one day and remained high during the whole suspension period, up to the 14th day. After 3 days of reloading following 14 days of antiorthostatic suspension, all of the above parameters significantly decreased compared to the control level. The difference between our data and the results by Bigard et al. [23] may be due to different duration of suspension. Nevertheless, the fact that it is the maximum respiration rate and the respiration rate on endogenous substrate that increases most suggests that the number of mitochondria and/or concentration of respiratory chain complexes therein could increase, which did not cause an increase of the basal respiration rate given the unchanged amount of endogenous substrates. This suggestion is evidenced by the increase of relative desmin content in the total protein that is required to determine localization of mitochondria and regulate their membrane permeability, and by the increase of content of other oxidizing ferments and mitochondrial creatine kinase [24]. However, the question remains about the reason of possible increase of expression of mitochondrial proteins in cardiomyocytes during antiorthostatic suspension at the earliest stages. With regard to soleus muscle fibre, the reasons for decreased cell respiration rate may be related to increased content of phosphorylated forms of high-energy phosphates in soleus fibers during microgravity conditions [47], which may cause reduced activity of $5^{\prime}$-adenosinemonophosphatedependent protease, which stimulates expression of mitochondrial proteins via the protein kinase cascade and regulates a number of other processes of energy metabolism [48]. But for soleus fibers mechanical tension decreased under suspension. Due to mechanical tension of cardiomyocytes increased under suspension, a reverse process may take place in cardiomyocytes. That could cause increased respiration rate, but another reason may not be ruled out. Thus, recent results in Goffart et al. [49] suggest that alpha-actinin-4 may be linked to the promotor area of the cytochrome gene $c$, causing higher expression thereof. Alpha-actinin-4 is nonmuscle isoform of alpha-actinin, a protein of the spectrin family [50]. It functions as an antiparallel homodimer, linking the ends of actin threads [51]. Furthermore, alphaactinin-4 links the actin cytoskeleton with the membrane and enables interoperation of the cortical cytoskeleton with cytoplasmic signal proteins [52].

In view of the above, we decided to analyze the structure of cortical cytoskeleton of cardiomyocytes during antiorthostatic suspension and subsequent reloading. AFM results suggest that, in the relaxed state, the transversal stiffness of the membrane with adjacent cortical cytoskeleton increased near the middle of the semisarcomere, that is, between the projections of the Z-disk and M-line after 1 day, and continued to increase during antiorthostatic suspension. The stiffness of the membrane in the Z-disk and M-line projection also grew, but somewhat later, that is, after 14 and 3 days of suspension, respectively. Increased stiffness of all parts of the membrane during activation of contraction and rigor of fibre remained the same as in the control group, which was expected because desmin content remained unchanged, as desmin enables transfer of tension from the contractile apparatus to the membrane of the cardiomyocyte.

Similarly to the results of Costa et al. [53] obtained using human aortic endothelium cells, it can be suggested that changes in transversal stiffness of cardiomyocytes are related to changes of the submembrane actin cytoskeleton, which is consistent with the data of Collinsworth et al. [54]. The increased transversal stiffness of the cortical cytoskeleton of cardiomyocytes may be related to increased content of nonmuscle actin isoforms (beta and gamma) and actin-binding proteins, particularly alpha-actinin-1 and alpha-actinin-4. Thus, it is known that alpha-actinin-1 is expressed in cardiomyocytes [55] and in skeletal muscle cells, along with alpha-actinin-4, at various stages of differentiation [49].

In order to verify this assumption (that increased transversal stiffness of the cortical cytoskeleton of cardiomyocytes may be linked to increased content of non-muscle actin isoforms), we have analyzed relative content of these proteins in the cytoplasmic and membrane fractions. Our results suggest that beta-actin content in the cytoplasmic and membrane fraction remained unchanged during antiorthostatic suspension and subsequent reloading. Gamma-actin content in the cytoplasmic fraction of proteins also remained the same as the control group level during suspension and reloading. However, gamma-actin content in the membrane fraction of proteins increased significantly on the first day of antiorthostatic suspension and continued to increase up to the 14th day, following the same trend as that of transversal stiffness. It should be noted that the increase of non-muscle F-actin (beta-actin) was observed in cat's cardiomyocytes during stimulated hypertrophy [56] although gamma-actin content was not measured.

At the same time, alpha-actinin-1 content in the cytoplasmic fraction of proteins decreased after 7 days of 
suspension, but increased in the membrane fraction. During 3 -day reloading following 14 days of antiorthostatic suspension, alpha-actinin-1 content in the membrane fraction decreased, while it increased in the cytoplasmic fraction and did not differ from the control group's level after 7 days of reloading in both fractions. At the same time, alpha-actinin4 content in the membrane fraction of proteins grew on the first day of antiorthostatic suspension and continued to increase up to the 14th day, and, starting from the third day, its content in the cytoplasmic fraction exceeded the control group level. During the reloading period, alpha-actinin-4 content in the membrane fraction fell to the control group level, and also decreased in the cytoplasmic fraction although it did not reach the control group level.

It should be noted that hardly anything is known about the role of non-muscle forms of alpha-actinin in skeletal muscle cells and cardiomyocytes. Nevertheless, there is evidence that the increase of relative alpha-actinin- 4 content in the cytoplasmic fraction is linked to the decrease of alphaactinin- 1 content, there and formation of a cancer pattern of fibroblasts [57]. Results exist suggesting that cancer transformation of cells, particularly lymphocytes, is accompanied by increased stiffness thereof, measured by an AFM [58]. Consequently, increased stiffness of the cells is related to the development of their submembrane cytoskeleton, reduction of alpha-actinin- 1 content and increase of alpha-actinin-4 content in the cytoplasmic fractions of proteins.

In the conclusion, to sum up our experimental results and the above discussion, we can hypothesize the following sequence of events in cardiomyocytes at early stages of antiorthostatic suspension and subsequent reloading after the end of experimental exposure. Increased volumetric load on the heart at early stages of antiorthostatic suspension causes deformation (stretching) of the cardiomyocyte, involving coordinated stretching of the contractile apparatus and the cortical cytoskeleton. Stretching of the contractile apparatus may cause smaller inter-filament spacing and, consequently, the observed increase of myofibril stiffness, which can be the reason for reduced contractility of the cardiomyocyte. Furthermore, we can suggest a hypothesis (that has to be proven experimentally) that stretching of the cortical cytoskeleton will cause dissociation of alpha-actinin-1 from submembrane actin, and initiate overexpression of nonmuscle actin and alpha-actinin-4, since the content of these two nonmuscle isoforms of alpha-actinin is interrelated. Increased content of non-muscle actin in the membrane fraction will require increased content of both isoforms of alpha-actinin in the membrane fraction as well to form the structure of the cortical cytoskeleton, which will be reflected in its increased stiffness that we observed in our experiments. At the same time, increased content of alpha-actinin- 4 in the cytoplasmic fraction that we observed may cause higher cytochrome $c$ content (but this suggestion needed in the experimental verification) and intensified cell respiration that we demonstrated. Since desmin is required for normal operation of mitochondria and oxidizing-phosphorylation processes, the increased desmin content is physiologically justified due to intensified cell respiration. At the same time, the processes will be reversed at early stages of reloading, as we observed in our experiments, because of the reverse fluid shift and reduced volumetric load on the heart.

Thus, in our study, we have determined the transversal stiffness of various parts of the contractile apparatus and the membrane with cortical cytoskeleton of rat's cardiomyocytes in the course of antiorthostatic suspension and subsequent reloading, as well as the cell respiration rate and relative content of alpha-actinin-2, desmin, non-muscle actin (beta and gamma), alpha-actinin-1, and alpha-actinin-4 in the membrane and cytoplasmic fractions of proteins. The above parameters describe structural and functional state of rat's cardiac muscle cells during antiorthostatic suspension and reloading, which led us to suggest a hypothetical mechanism of reaction of these cells to changes in external conditions, which requires further research to be experimentally confirmed.

\section{Acknowledgments}

The financial support of the Russian Foundation of Basic Research (RFBR Grant 10-04-00106-a) and program of fundamental research SSC RF-IBMP RAS greatly acknowledged. No conflict of interests are declared by the authors.

\section{References}

[1] W. E. Thornton, T. P. Moore, and S. L. Pool, "Fluid shifts in weightlessness," Aviation Space and Environmental Medicine, vol. 58, no. 9, pp. A86-90, 1987.

[2] D. E. Watenpaugh and A. R. Hargens, "The cardiovascular system in microgravity," in Handbook of Physiology. Environmental Physiology, vol. 4 of American Physiological Society, no. I, part 3, chapter 29, pp. 631-674, 1996.

[3] J. V. Nixon, R. G. Murray, C. Bryant et al., "Early cardiovascular adaptation to simulated zero gravity," Journal of Applied Physiology, vol. 46, pp. 541-548, 1979.

[4] M. W. Bungo, D. J. Goldwater, R. L. Popp, and H. Sandler, "Echocardiographic evaluation of space shuttle crewmembers," Journal of Applied Physiology, vol. 62, no. 1, pp. 278-283, 1987.

[5] J. B. Charles and C. M. Lathers, "Cardiovascular adaptation to spaceflight," Journal of Clinical Pharmacology, vol. 31, no. 10, pp. 1010-1023, 1991.

[6] E. R. Morey, E. E. Sabelman, R. T. Turner, and D. J. Baylink, "A new rat model simulating some aspects of space flight," Physiologist, vol. 22, no. 6, pp. S23-24, 1979.

[7] E. Morey-Holton, R. K. Globus, A. Kaplansky, and G. Durnova, "The hindlimb unloading rat model: literature overview, technique update and comparison with space flight data," Advances in Space Biology and Medicine, vol. 10, pp. 740, 2005.

[8] A. R. Hargens, J. Steakai, C. Johansson, and C. M. Tipton, "Tissue fluid shift, forelimb loading, and tail tension in tailsuspended rats," Physiologist, vol. 27, supplement, pp. S37S38, 1984.

[9] X. J. Musacchia, D. R. Deavers, and G. A. Meininger, "Fluid/ electrolyte balance and cardiovascular responses: head-down tilted rats," Physiologist, vol. 33, no. 1, pp. S46-47, 1990.

[10] K. S. McDonald, M. D. Delp, and R. H. Fitts, "Effect of hindlimb unweighting on tissue blood flow in the rat," Journal of Applied Physiology, vol. 72, no. 6, pp. 2210-2218, 1992. 
[11] F. G. Shellock, H. J. C. Swan, and S. A. Rubin, "Early central venous pressure changes in the rat during two different levels of head-down suspension," Aviation Space and Environmental Medicine, vol. 56, no. 8, pp. 791-795, 1985.

[12] G. Halet, P. Viard, J. L. Morel, J. Mironneau, and C. Mironneau, "Effects of hindlimb suspension on cytosolic $\mathrm{Ca}^{2+}$ and $\left[{ }^{3} \mathrm{H}\right]$ ryanodine binding in cardiac myocytes," American Journal of Physiology, vol. 276, no. 4, pp. H1131-H1136, 1999.

[13] W. Yin, J. C. Liu, R. Fan et al., "Modulation of $\beta$-adrenoceptor signaling in the hearts of 4 -wk simulated weightlessness rats," Journal of Applied Physiology, vol. 105, no. 2, pp. 569-574, 2008.

[14] Y. Cui, S.-M. Zhang, Q.-Y. Zhang et al., "Modulation of intracellular calcium transient in response to $\beta$-adrenoceptor stimulation in the hearts of 4 -wk-old rats during simulated weightlessness," Journal of Applied Physiology, vol. 108, no. 4, pp. 838844, 2010.

[15] S. Fagette, M. Lo, C. Gharib, and G. Gauquelin, "Cardiovascular variability and baroreceptor reflex sensitivity over a 14-day tail suspension in rats," Journal of Applied Physiology, vol. 78, no. 2, pp. 717-724, 1995.

[16] J. Chen, L. F. Zhang, and J. Ma, "Ultrastructural changes of myocardium in long-term tail-suspended rats," in Chinese Journal of Aerospace Medicine, vol. 6, pp. 133-137, 1995.

[17] L. F. Zhang, "Experimental studies on effects of simulated weightlessness on myocardial function and structure," Journal of Gravitational Physiology, vol. 1, no. 1, pp. P133-P136, 1994.

[18] L. F. Zhang, Z. B. Yu, and J. Ma, "Functional alterations in cardiac muscle after medium- or long-term simulated weightlessness and related cellular mechanisms," Journal of Gravitational Physiology, vol. 2, no. 1, pp. P5-P8, 1995.

[19] Z. B. Yu, J.-X. Bao, J. Ma, L.-F. Zhang, and J.-P. Jin, "Changes in myocardial contractility and contractile proteins after four weeks of simulate weightlessness in rats," Journal of Gravitational Physiology, vol. 7, no. 2, pp. P147-P148, 2000.

[20] A. W. Dunlap, D. B. Thomason, V. Menon, and P. A. Hofmann, "Decreased $\mathrm{Ca}^{2+}$ sensitivity of isometric tension in skinned cardiac myocytes from tail-suspended rats," Journal of Applied Physiology, vol. 80, no. 5, pp. 1612-1617, 1996.

[21] D. Desplanches, M. H. Mayet, B. Sempore, J. Frutoso, and R. Flandrois, "Effect of spontaneous recovery or retraining after hindlimb suspension on aerobic capacity," Journal of Applied Physiology, vol. 63, no. 5, pp. 1739-1743, 1987.

[22] J. M. Overton, C. R. Woodman, and C. M. Tipton, "Effect of hindlimb suspension on $\mathrm{V}^{\cdot} \mathrm{O}_{2}(\max )$ and regional blood flow responses to exercise," Journal of Applied Physiology, vol. 66, no. 2, pp. 653-659, 1989.

[23] A.-X. Bigard, E. Boehm, V. Veksler, P. Mateo, K. Anflous, and R. Ventura-Clapier, "Muscle unloading induces slow to fast transitions in myofibrillar but not mitochondrial properties. Relevance to skeletal muscle abnormalities in heart failure," Journal of Molecular and Cellular Cardiology, vol. 30, no. 11, pp. 2391-2401, 1998.

[24] T. Kunishima, "Ultrastructural and biochemical enzymatic properties of right ventricular muscles during hindlimb suspension in rats," Journal of the Physiological Society of Japan, vol. 55, no. 4, pp. 153-164, 1993.

[25] I. V. Ogneva, "Transversal stiffness and beta-actin and alphaactinin-4 content of the $\mathrm{m}$. Soleus fibers in the conditions of a 3-day reloading after 14-day gravitational unloading," Journal of Biomedicine and Biotechnology, vol. 2011, Article ID 393405, 7 pages, 2011.

[26] S. C. Lieber, N. Aubry, J. Pain, G. Diaz, S.-J. Kim, and S. F. Vatner, "Aging increases stiffness of cardiac myocytes measured by atomic force microscopy nanoindentation," American Journal of Physiology, vol. 287, no. 2, pp. H645-H651, 2004.

[27] J. Zhu, T. Sabharwal, A. Kalyanasundaram, L. Guo, and G. Wang, "Topographic mapping and compression elasticity analysis of skinned cardiac muscle fibers in vitro with atomic force microscopy and nanoindentation," Journal of Biomechanics, vol. 42, no. 13, pp. 2143-2150, 2009.

[28] I. V. Ogneva, D. V. Lebedev, and B. S. Shenkman, "Transversal stiffness and young's modulus of single fibers from rat soleus muscle probed by atomic force microscopy," Biophysical Journal, vol. 98, no. 3, pp. 418-424, 2010.

[29] I. V. Ogneva, "Transversal stiffness of fibers and desmin content in leg muscles of rats under gravitational unloading of various durations," Journal of Applied Physiology, vol. 109, no. 6, pp. 1702-1709, 2010.

[30] V. A. Saks, V. I. Veksler, A. V. Kuznetsov et al., "Permeabilized cell and skinned fiber techniques in studies of mitochondrial function in vivo," Molecular and Cellular Biochemistry, vol. 184, no. 1-2, pp. 81-100, 1998.

[31] E. K. Seppet, M. Eimre, T. Andrienko et al., "Studies of mitochondrial respiration in muscle cells in situ: use and misuse of experimental evidence in mathematical modelling," Molecular and Cellular Biochemistry, vol. 256-257, no. 1-2, pp. 219-227, 2004.

[32] R. Vitorino, R. Ferreira, M. Neuparth et al., "Subcellular proteomics of mice gastrocnemius and soleus muscles," Analytical Biochemistry, vol. 366, no. 2, pp. 156-169, 2007.

[33] H. Towbin, T. Staehelin, and J. Gordon, "Electrophoretic transfer of proteins from polyacrylamide gels to nitrocellulose sheets: procedure and some applications," Proceedings of the National Academy of Sciences of the United States of America, vol. 76, no. 9, pp. 4350-4354, 1979.

[34] N. Akiyama, Y. Ohnuki, Y. Kunioka, Y. Saeki, and T. Yamada, "Transverse stiffness of myofibrils of skeletal and cardiac muscles studied by atomic force microscopy," Journal of Physiological Sciences, vol. 56, no. 2, pp. 145-151, 2006.

[35] M. Stewart, K. Franks-Skiba, and R. Cooke, "Myosin regulatory light chain phosphorylation inhibits shortening velocities of skeletal muscle fibers in the presence of the myosin inhibitor blebbistatin," Journal of Muscle Research and Cell Motility, vol. 30, no. 1-2, pp. 17-27, 2009.

[36] A. Persechini, J. T. Stull, and R. Cooke, "The effect of myosin phosphorylation on the contractile properties of skinned rabbit skeletal muscle fibers," Journal of Biological Chemistry, vol. 260, no. 13, pp. 7951-7954, 1985.

[37] I. Matsubara, Y. E. Goldman, and R. M. Simmons, "Changes in the lateral filament spacing of skinned muscle fibres when cross-bridges attach," Journal of Molecular Biology, vol. 173, no. 1, pp. 15-33, 1984.

[38] S. Xu, B. Brenner, and L. C. Yu, "State-dependent radial elasticity of attached cross-bridges in single skinned fibres of rabbit psoas muscle," Journal of Physiology, vol. 465, pp. 749765, 1993.

[39] K. W. Ranatunga, N. S. Fortune, and M. A. Geeves, "Hydrostatic compression in glycerinated rabbit muscle fibers," Biophysical Journal, vol. 58, no. 6, pp. 1401-1410, 1990.

[40] D. L. Enns, T. Raastad, I. Ugelstad, and A. N. Belcastro, "Calpain/calpastatin activities and substrate depletion patterns during hindlimb unweighting and reweighting in skeletal muscle," European Journal of Applied Physiology, vol. 100, no. 4, pp. 445-455, 2007.

[41] K. S. McDonald and R. H. Fitts, "Effect of hindlimb unloading on rat soleus fiber force, stiffness, and calcium sensitivity," 
Journal of Applied Physiology, vol. 79, no. 5, pp. 1796-1802, 1995.

[42] Y. Capetanaki, R. J. Bloch, A. Kouloumenta, M. Mavroidis, and S. Psarras, "Muscle intermediate filaments and their links to membranes and membranous organelles," Experimental Cell Research, vol. 313, no. 10, pp. 2063-2076, 2007.

[43] L. Rappaport, P. Oliviero, and J. L. Samuel, "Cytoskeleton and mitochondrial morphology and function," Molecular and Cellular Biochemistry, vol. 184, no. 1-2, pp. 101-105, 1998.

[44] Y. Capetanaki and D. J. Milner, "Desmin cytoskeleton in muscle integrity and function," Sub-Cellular Biochemistry, vol. 31, pp. 463-495, 1998.

[45] D. J. Milner, M. Mavroidis, N. Weisleder, and Y. Capetanaki, "Desmin cytoskeleton linked to muscle mitochondrial distribution and respiratory function," Journal of Cell Biology, vol. 150, no. 6, pp. 1283-1298, 2000.

[46] V. A. Saks, A. Kuznetsov, T. Andrienko et al., "Heterogeneity of ADP diffusion and regulation of respiration in cardiac cells," Biophysical Journal, vol. 84, no. 5, pp. 3436-3456, 2003.

[47] Y. Ohira, W. Yasui, F. Kariya et al., "Metabolic adaptation of skeletal muscles to gravitational unloading," Acta Astronautica, vol. 33, pp. 113-117, 1994.

[48] W. W. Winder, "Energy-sensing and signaling by AMPactivated protein kinase in skeletal muscle," Journal of Applied Physiology, vol. 91, no. 3, pp. 1017-1028, 2001.

[49] S. Goffart, A. Franko, C. S. Clemen, and R. J. Wiesner, " $\alpha$ actinin 4 and BAT1 interaction with the Cytochrome c promoter upon skeletal muscle differentiation," Current Genetics, vol. 49, no. 2, pp. 125-135, 2006.

[50] M. J. F. Broderick and S. J. Winder, "Towards a complete atomic structure of spectrin family proteins," Journal of Structural Biology, vol. 137, no. 1-2, pp. 184-193, 2002.

[51] H. Youssoufian, M. McAfee, and D. J. Kwiatkowski, "Cloning and chromosomal localization of the human cytoskeletal $\alpha$ actinin gene reveals linkage to the $\beta$-spectrin gene," American Journal of Human Genetics, vol. 47, no. 1, pp. 62-72, 1990.

[52] M. D. Baron, M. D. Davison, P. Jones, and D. R. Critchley, "The structure and function of alpha-actinin," Biochemical Society Transactions, vol. 15, no. 5, pp. 796-798, 1987.

[53] K. D. Costa, A. J. Sim, and F. C. P. Yin, "Non-Hertzian approach to analyzing mechanical properties of endothelial cells probed by atomic force microscopy," Journal of Biomechanical Engineering, vol. 128, no. 2, pp. 176-184, 2006.

[54] A. M. Collinsworth, S. Zhang, W. E. Kraus, and G. A. Truskey, "Apparent elastic modulus and hysteresis of skeletal muscle cells throughout differentiation," American Journal of Physiology, vol. 283, no. 4, pp. C1219-C1227, 2002.

[55] C. Velez, A. E. Aranega, J. C. Prados, C. Melguizo, L. Alvarez, and A. Aranega, "Basic fibroblast and platelet-derived growth factors as modulators of actin and $\alpha$-actinin in chick myocardiocytes during development," Proceedings of the Society for Experimental Biology and Medicine, vol. 210, no. 1, pp. 57-63, 1995.

[56] S. Balasubramanian, S. K. Mani, H. Kasiganesan, C. C. Baicu, and D. Kuppuswamy, "Hypertrophic stimulation increases $\beta$ actin dynamics in adult feline cardiomyocytes," PLoS ONE, vol. 5, no. 7, Article ID e11470, 2010.

[57] K. Honda, T. Yamada, R. Endo et al., "Actinin-4, a novel actin-bundling protein associated with cell motility and cancer invasion," Journal of Cell Biology, vol. 140, no. 6, pp. 1383 1393, 1998.

[58] X. Cai, J. Cai, S. Dong, H. Deng, and M. Hu, "Morphology and mechanical properties of normal lymphocyte and Jurkat revealed by atomic force microscopy," Shengwu Gongcheng
Xuebao/Chinese Journal of Biotechnology, vol. 25, no. 7, pp. 1107-1112, 2009. 

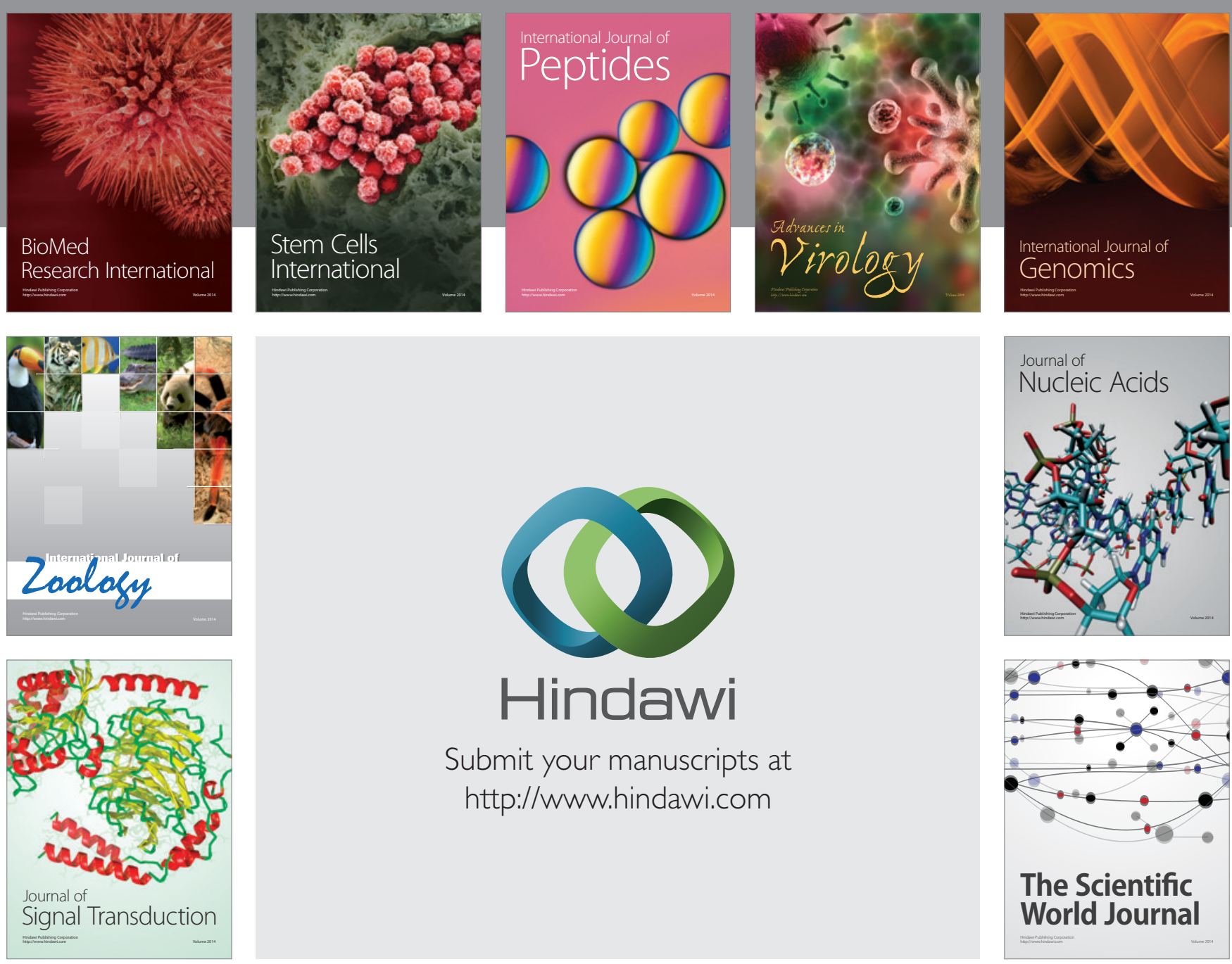

Submit your manuscripts at

http://www.hindawi.com
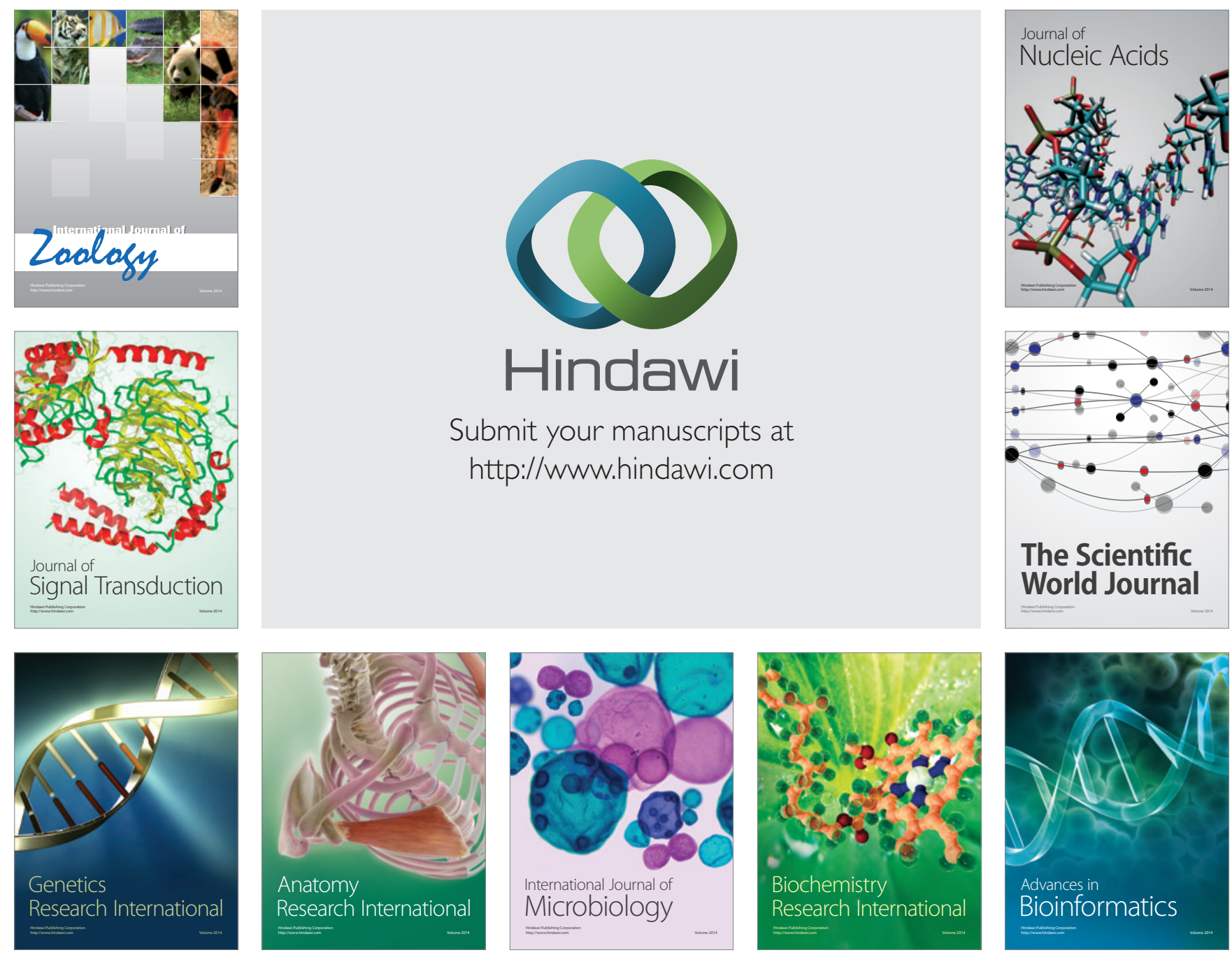

The Scientific World Journal
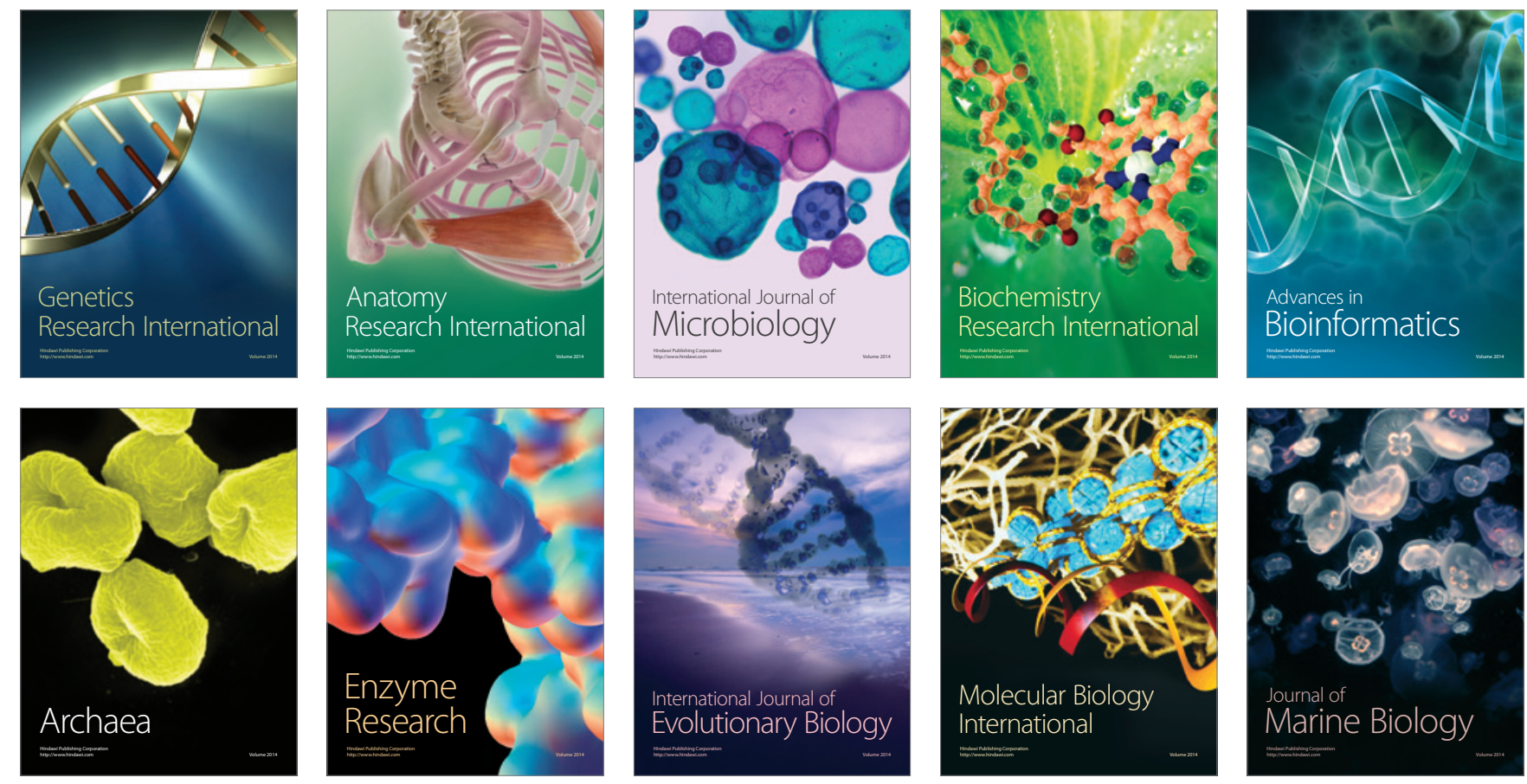